\title{
Success Factors and Problems Encountered in the Workplace Learning of University/College of Technology Students in Taiwan: A Five-Star Hotel as an Example
}

\author{
Mey-Tyng Wang and Guo-Hong Lei \\ Department of Technology Application and Human Resource Development \\ National Taiwan Normal University \\ libra@gate.sinica.edu.tw, Bernie23203@yahoo.com.tw
}

\begin{abstract}
In order to help students in universities/colleges of technology close the education-employment gaps, Taiwan's educational authorities promoted workplace-learning programs. However, what are the success factors and problems encountered? This article reaches three defined conclusions: 1) student can internalize knowledge and skills over time, and apply them to workplace except for improving performance; 2) student can develop initiative characters, improve innovation, and even activate industries to think with novel ideas; 3) and, the lacking earnest attitude as well as deficiency of communication ability affect the performance which should be. Following with these conclusions, three recommendations are offered: 1) it would be proper to strengthen student's professional intellect for future development; 2) it would be proper to strengthen student's vocational capability in practice, including individual personality; 3 ) and, it would be proper to offer related testing or scaling tools to help student get awareness and thus upgrade their attitude during workplace-learning.
\end{abstract}

Keywords: university/college of technology, workplace learning, success factor, hospitality industry.

\section{$1 \quad$ Introduction}

Due to the widespread of higher education, upgrading of vocational technical education, and the changing of economics, society, and enterprise structure, it is necessary for high level vocational education institutions-including university/college of technology, and junior college of technology-to adapt themselves timely. Not only the teaching of vocational education institutions have to be implemented under such principles that discriminate none and cater to specific nature of the individual, but also those vocational education institutions have to face changing manpower needs in business, as well as to coordinate with government policy. Therefore, The most significant difference between vocational education institutions and general universities is that vocational education institutions emphasis pragmatic approach that s gaps between learning and performance, and combine theory and practicein order that students could be capable of applying their skills and capability to workplace (Ministry of Education, 2010a). 
There were critics that most higher education students have difficulty to join in the workplace after graduation. Under government policy, universities/colleges of technology currently are strengthening their internship programs in order to help students to experience workplace earlier, shorten career exploring period, recognize what workplace needs, establish correct working attitude, and thus expand their career opportunities. As a result, it would be necessary and realistic trend forthe school to pay attention on WL. However, in the light of the fact that there are so many WL approaches, it is worth to understand if those approaches could effectively help students to learn in WL, and benefit both of students and industry. Therefore, this research aims to: 1) understand the factors leading to success in WL for students in universities/colleges of technology; and 2) understand what WL obstacles that those students would encounter. Via literature review as well as interviews with students and managerial level of a hotel, this research also aims to provide the schools and industries involving in WL program with suggestions and recommendations.

\section{$2 \quad$ Literature Review}

\subsection{Current Condition and Trend of WL in Taiwan}

In a broad sense, WL includes learning activities in workplace, semi-workplace, and community. In the US, the most popular six categories of internship that university/college students participate in are: cooperative education (co-op), field experience, practicum, service learning, externship, and apprenticeship (Lee, L. S., \& Lai, C. C., 2011, quoted from WetFeet, u.d.). Among these six categories, cooperative education is a policy mode promoted by government and is also a strategic integration of higher education and the industry. And as Meng (2003) points out, it is a kind of cooperation between the industries and schools. Encompassing their main subjects, the design of WL is to encourage students go to workplace to meet development requirements of individual career and professional skill (Linn, Ferguson, \& Egart, 2004). Despite of different modes, WL could still help students to utilize their knowledge, intellects, and interpersonal relationship to have a real-world view of workplace earlier. Furthermore, along with the refined curricula designs for students, a proper combination of academic intellects and working experience could be achieved by giving high commitment, as well as offering suitable working environment (Parsons, Caylor, \& Simmons, 2005). Taiwan's Ministry of Education has integrated cooperative education-related affairs, such as off campus internship, college-internship matchmaking, industry's participation of internship mechanism, and competence rebuilding, into a unified program (Ministry of Education, 2010c). The promulgation of Off-Campus Students Internship Implementation Program (amendment) in 21 January, 2011 by the Ministry aims to offer experiential learning earlier to establish proper attitude towards work for students, increase pragmatic teaching resources for the school and career positions for students, and reduce orientation training cost for the industry (Ministry of Education, 2011).

\subsection{Situated Learning Perspectives}

Under the concept of cooperative education, WL aims to form a real situation, in which situated learning model could be used to improve the students' learning effectiveness, 
and provide the educators with different thinking in order to inspire more innovative teaching approaches. Situated learning is considered as a society participation process, and both community and culture would affect the members' learning models. During this socialization process, the interaction between experienced and inexperienced members would deliver recessive and dominant knowledge and then a common interpretation of a matter could be reached (Lave \& Wenger, 1991). In terms of workplace, learning behaviors could be seen in every aspect of WL situation, and the learning effectiveness could be evaluated by degree of participation. By doing so, students who have different learning requirements could have more understandings about the diversity and difference of education. Therefore, situated learning put the emphasis on realized relations between learning and social culture, as well as the interaction between learners and environment, and thus the efficiency of WL could be improved.

\subsection{Factors Leading to Successful WL}

Critical factors leading to successful WL could be divided into absorptive capacity in workplace and mission objectives for WL. WL is not only limited in schools, but also includes internships based on cooperative education; thus, through WL, students could combine theory and practice, and then transform and apply learned knowledge, skill and capacity (Hui-Hua Chiu, 2006). Therefore, students have to firstly acquire related knowledge and skills, follow with the process of self-transform and internalize, and then apply learned knowledge and skills to WL.

\subsubsection{Perspective of Absorptive Capacity}

Due to the perspective of absorptive capacity (ACAP) proposed by Zahra and Gerard (2002), the importance of absorptive capacity has caught those eyes of strategic management, technology management, international business, and organizational economics. There are two forms of absorptive capacity: potential absorptive capacity (PACAP) and realized absorptive capacity(RACAP). PACAP includes knowledge acquisition and assimilation capacities; while RACAP includes knowledge transformation and exploitation. A model of ACAP is as figure 1.

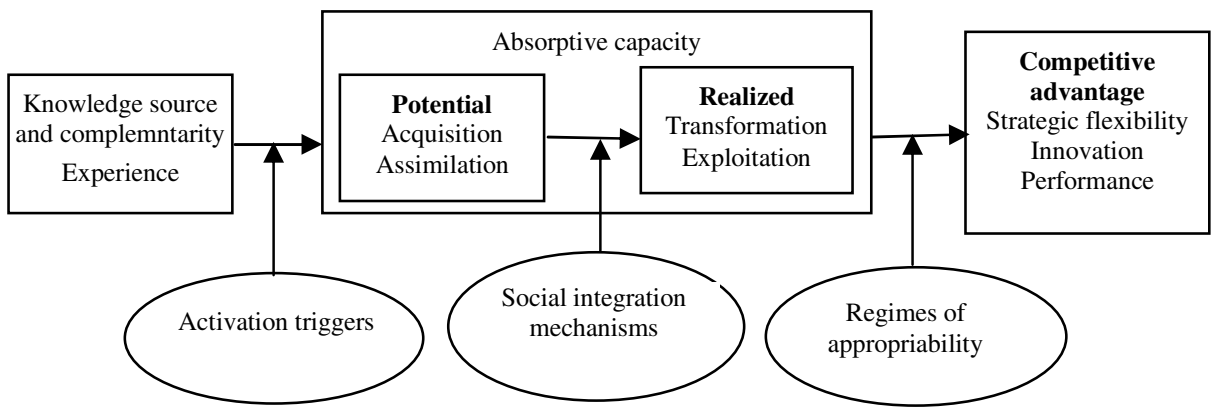

Fig. 1. A model of ACAP Source: Zahra \& Gerard, 2002 


\subsubsection{Systemic View of WL}

According to "What Makes for Good Workplace Learning" prepared by Australian National Training Authority, ANTA (2003), the ultimate goal of WL should be business competitiveness and innovative capacity. An ideal WL, some important channels such as networks and partnerships should be included. These channels will be transformed, after socialized process, into capability to reach the WL goals of improving competitiveness and innovative capacity. A systemic view of workplace learning is as figure 2 .

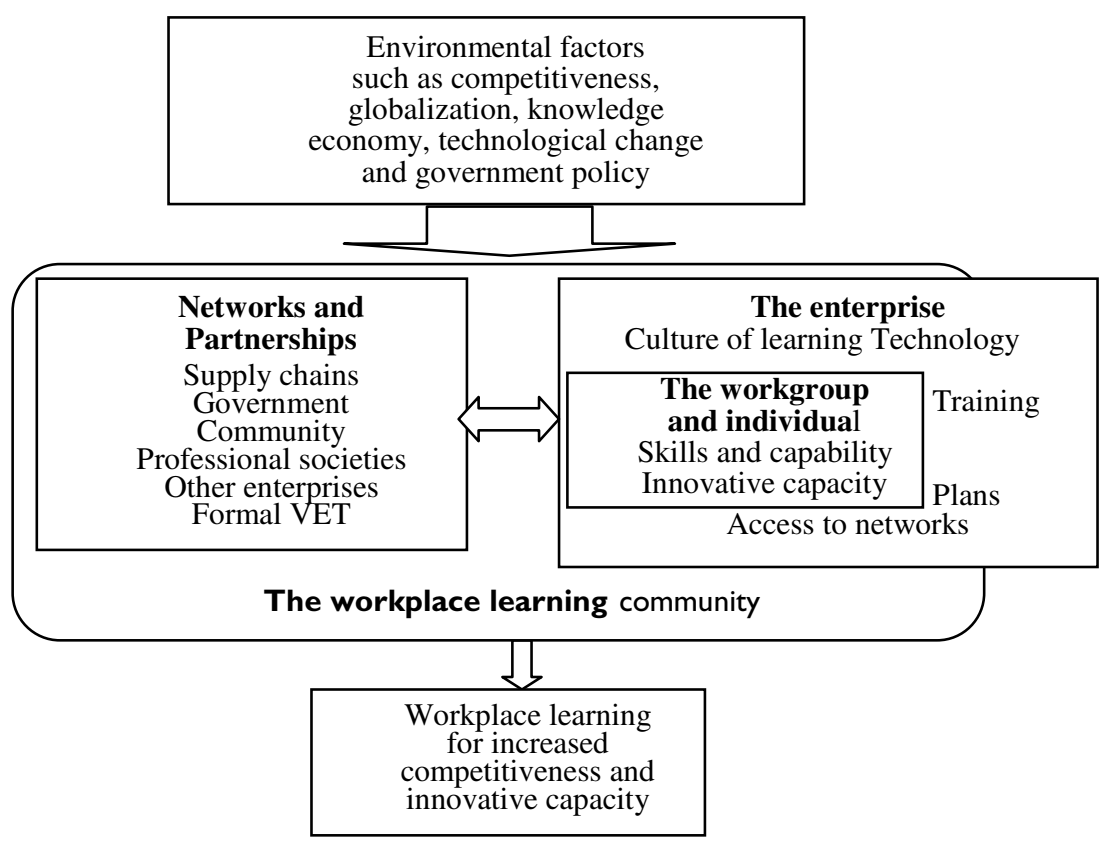

Fig. 2. A systemic view of workplace learning

Source: NCVER, 2003

\section{$3 \quad$ Findings and Discussion}

This research put the emphasis on tourism-one of the Six Key Emerging Industries. Therefore, the authors specifically choose a five-start hotel locates in northern Taiwan as research subject regarding its good transportation location and the worldwide business service it provides. The hotel cooperate with eight universities/colleges of technology, and there are 24 students participating in WL. Through case studies and semi-constructive interview, the authors interview with participants who join cooperative education, including one senior manager, one administrative personnel, and three internship students in third or forth grade of college/university. Questionnaire writings 
are prepared in accordance with literature review and research outlines. If uncertainties are found during the review of interview materials, there will be e-mails or telephone calls to enquire further information to make sure that all contents in questionnaire are keeping in consistence and meeting the requirements of this research so that this research could contribute to credibility and validity. After systematically sorting out, factors leading to success or problems resulting from obstacle in WL for students of universities/colleges of technology are detailed below.

\subsection{Factors Leading to Success in Workplace for Students of Universities/Colleges of Technology}

\subsubsection{Students' Capabilities to Absorb, Internalize, and Apply}

Analysis in this research consists with the theories raised by Zahra \& Gerard (2002), and Lave \& Wenger (1991).Students could acquire knowledge from school, gain practical experiences of society from hotel, merge them together and then to apply them in the workplace.

\subsubsection{Five-Start Hotel Can Lead to Innovation Skills}

Analysis in this research consists with the theory raised by ANTA (2003). It shows that active and practical learning could improve the innovative capacity for students and activate the innovative thinking for the industry; meanwhile, the hotel could also offer professional trainings to improve practical operation capability.

\subsection{Problems Resulting from Obstacle in Workplace Learning for Students in Universities/Colleges of Technology}

\subsubsection{Theory Learned in School Could Be Applied to Hotel Business in Those But Could Not Improve Its Effectiveness}

In the interview results, show that professional knowledge teaching remains inadequate due to students' desire for more professional knowledge. The above information represents that professional knowledge could only be applied to basic practices in the industry but could not improve its effectiveness, which means that the mission objectives of the industry could not be reached. This also demonstrates that the knowledge learned in the school could not reach ANTA's perspective of a WL that could improve competitiveness (ANTA, 2003).

\subsubsection{Deficiency of Communication Ability}

The environment of global competition requires the capability performing with knowledge, skills, and attitudes (Hunter, 2004; Schejbal \& Irvine, 2009). Analysis against interview results that students are lacking basic knowledge and proper attitude. As a result, students need to be more capable in terms of communication, language, and positive attitude. 


\section{Conclusion and Suggestions}

\subsection{Conclusions}

\subsubsection{Student Could Internalize Knowledge and Skills over Time, and Apply} Them to Workplace Except for Improving Effectiveness

By internalizing professional knowledge and practice, the students could flexibly apply their knowledge and experiences to workplace and accomplish general working mission and goals. However, in terms of cost saving and improving service quality, the effectiveness is limited.

\subsubsection{Student Could Develop Initiative Characters, Improve Innovation, and Even Activate the Industry to Think with Novel Ideas}

Students would be more capable after receiving basic professional knowledge, and know how to reason and logically analyze, systematically criticize, and make decision. By experiencing practical operation in hotel, active and energetic students who have received multi-dimensional trainings would become more flexible. Their innovative capability would be also upgraded.

\subsubsection{The Lacking Earnest Attitude as Well as Deficiency of Communication Ability Would Affect the Performance Which Should Be}

The quality and effectiveness of students in workplace are largely decided by their attitudes and communicating capacity, such as values, oral expression, listening, English speaking, respect and acceptance, interaction with people from different departments, interpersonal relationship, and teamwork.

\subsection{Suggestions}

\subsubsection{It Would Be a Proper Way to Strengthen Student's Professional Intellect for Further Development}

Facing different unexpected situations, students would usually respond with being at a loss or unable to react. As a result, it would be better for hotel to offer more advanced training in legal knowledge, management skills, service professions, cost control. By doing so, related rights of both students and business owner could be protected, the students could also have more opportunities to shorten the adaptation period because they have become more capable of multiple capabilities as well as competitiveness.

\subsubsection{It Would Be a Proper Way to Strengthen Student's Vocational Capabili- ty in Practice, Including Individual Personality}

Universities/colleges of technology should consider efforts to improve students' positive mind and characters, empathy and sense of morality, values judging, recognizing professional functions of business organization, in order to strengthen their capabilities in practical operation. Additionally, students should be encouraged to share, 
exchange the knowledge the have learned, and join healthy activities such as professional speech, preschool or nursing home visiting.

\subsubsection{It Would Be a Proper Way to Offer Related Testing or Scaling Tools to Help Student Gaining Awareness and Thus Upgrade Their Attitude during Workplace Learning}

Hotel managers are encouraged to provide aptitude test before conducting interview. If any student with negative attitude are found during interview, hotel managers are advised to explain to him/her the hardship would have to face in order to reduce the possibility that students might not be able to accomplish mission and thus the effectiveness could be improved.

\section{References}

1. Australian National Training Authority: What makes for good workplace learning (2003), http: / / www. ncver. edu.au/publications/1004.html (retrieved December 3, 2010)

2. Chiu, H.H.: An Empirical Study on Relationship Among Learning Environment, Personal Attributes and Absorptive Capacity - An Example of Students from Department of Hotel and Restaurant Management of S School Under Rotary Cooperative Education Program. Unpublished master's thesis, Shu-Te University, Kaohsiung (2006)

3. Hunter, W.D.: Knowledge, skills, attitudes, and experiences necessary to become globally competent. Unpublished doctoral dissertation, Lehigh University, Bethlehem, PA (2004), http: / / www.globalcompetence.org/pub-pres / HunterDissertation.pdf (retrieved October 10, 2011)

4. Meng, J.-L.: New Thinking for Academic-Industry Collaboration. Technological and Vocational Education Bimonthly 76, 17-20 (2003)

5. Lave, J., Wenger, E.: Situated learning: legitimate peripheral participation. Cambridge University Press, New York (1991)

6. Lee, L.S., Lai, C.C.: The Improvement towards Technical Colleges off-campus Internship Design. Quarterly Journal of Technological and Vocational Education 1(3), 1-5 (2011)

7. Lin, J.C.: Four Major Strategies for Workplace Learning. T\&D Fashion 31, 1-5 (2005)

8. Linn, P.L., Ferguson, J., Egart, K.: Career exploration via cooperative education and lifespan occupational choice. Journal of Vocational Behavior 65(3), 430-447 (2004)

9. Ministry of Education: New Program for Technical Education-Cultivating Excellent Professional Personnel, Department of Technological \& Vocational Education (2010a),

http: / / www. tve.edu.tw/Public/Publish/ 20102251128375334 .pdf (retrieved October 15, 2010)

10. Ministry of Education: MOE Promotes Academic-Industry Collaboration Plan, Department of Technological \& Vocational Education (2010b), http: / / www. tve. edu. tw/ HotNews . asp?News Id=276 (retrieved November 19, 2010)

11. Ministry of Education: MOE Grant Directions Regarding Technical College off-camp Internship (Amended on January 1, 2011), http://edu.law.moe.gov.tw/ LawContentDetails . aspx?id=FL050926\&KeyWordHL=\&StyleType=1 (retrieved February 20, 2012) 
12. Parsons, C.K., Caylor, E., Simmons, H.S.: Cooperative Education Work Assignments: The role of organizational and individual factors in enhancing ABET competencies and co-op workplace well-being. Journal of Engineering Education 94(3), 309-318 (2005)

13. Schejbal, D., Irvine, G.: Global Competencies, Liberal Studies, and the Needs of Employers. Continuing Higher Education Review (The Journal of the University Continuing Education Association) 73, 125-142 (2009)

14. Zahra, S.A., George, G.: Absorptive Capacity: A review, reconceptualization, and extension. Academy of Management Review 27(2), 185-203 (2002),

http://frontiers.sauder.ubc.ca/Zahra_George_AMR_2002.pdf (retrieved December 3, 2010) 